\title{
Comparison of Gears Manufactured by Stir Casting, Machining,and Importance of Stir Welding
}

\author{
T.G.Loganathan, R.Praveen, G.Ashwanth, N.Lokesh Siddavatam Nishanth Reddy, Mulavayal Dhanush \\ Dept. of Mechanical Engineering, R.M.K College of Engineering and Technology, \\ Thiruvallur, Chennai - 601206 \\ loganathan@rmkcet.ac.in
}

\begin{abstract}
In the last few decades, the global era has been shifted from matrix composites to Metal Matrix Composites. Due to their diversified properties, they are being used in different sectors including majors as automobile, aerospace, and defense. Some most important properties include good mechanical properties, low density, and better corrosion properties as compared to conventional metals andin the last few decades, the scientific approach towards matrix composites changed significantly due to the door unlocks in the diversified field of research for composites. Stir Casting is a liquid state method of composite materials fabrication, in which a dispersed phase (ceramic particles, short fibers) is mixed with a molten matrix metal utilizing mechanical stirring. The stir casting process is a promising technique for the production of composites. This paper provides a comparison ofthe fabrication of gears
\end{abstract}

Keywords: Casting; Stir casting; Gear

\section{Introduction}

In the last few decades, the scientific approach towards matrix composites changed significantly due to the doors unlocked in the diversified field of research for composites. The need for the search for new composite materials arises due to highly specific properties that can be achieved in composites for a specialized task and another fact that the world is going to suffer in the future due to its limited resources of fuel. Concerning fuel consumption now we require materials that are light in weight and can sustain very high strength in the industry. Since our fuel assets are depleting very quickly, we are in need to identify methods of fabricating without compromising quality [1-4]. The need for the search for new composite materials arises due to highly specific properties that can be achieved in composites for a specialized task and another fact that the world is going to suffer in the future due to its limited resources of fuel. If talking concerning fuel consumption now we require materials that are light in weight and withstand high strength in the aerospace and automobile industry especially due to important deciding factor of fuel consumption. Since our fuel assets degrading at a significant rate in which major of them are finite resources. It's the zeal to search for composite materials. Matrix composites are continuous and uniform. Reinforcement is the material that is embedded in the matrix. Reinforcements can be added in the form of monofilaments or discontinuous forms of short fibers, whiskers, particulates, etc. These are materials composed of two phases, matrix phase, and dispersed phase. Matrix composites are composite materials in which a major portion is in matrix form and reinforcement is added to it to enhance its properties. Matrix is continuous and uniform. Reinforcement is the material that is embedded in the matrix. Reinforcements can be added in the form of monofilaments or discontinuous forms of short fibers, whiskers, particulates, etc. Metal matrix composites are composite materials that are composed of two phases, matrix phase, and dispersed phase. The reinforcement material is embedded into the matrix. Stir Casting is a technique in which short fibers are mixed with molten metal by stirring. Friction stir welding is also one of the processes which can be used to weld non-ferrous materials. It is also called as environmental friendly process [5-7].

\section{Stir Casting Method}

In stir casting, we use a stirrer to agitate the molten metal matrix (Figure 1). One end of the stirring rod is connected to the impeller and another end is connected to the shaft of the motor. The resultant molten metal is then poured intoa die for casting.[1] A major concern is associated with stir casting is the segregation of reinforcement particles due to various process parameters and material properties resulting in the nonhomogeneous metal distribution. The various process parameters andthe particle suspension in the metal matrix are governed by the velocity and angle of the stirrer to a greater extent. Metal is heated over the liquid temperature so that it reaches the molten state. Preheated particles are further includedinthe molten matrix and mixed thoroughly with each other [4]. 

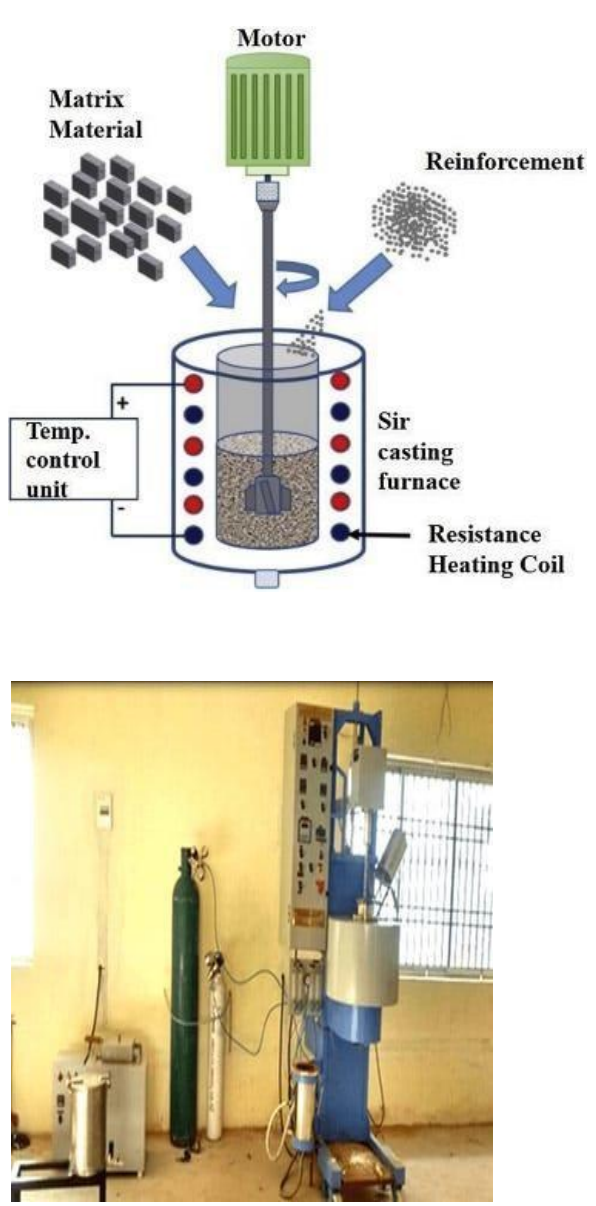

Figure 1. Stir Casting setup

\subsection{Factors Affecting the Process}

Information collected through various research papers shows the following factors which affect the stir casting process the most. They are

1. Speed of stirring

2. Time duration of stirring

3. Stirring temperature

\section{A. Speed of Stirring}

It is reported by several authors that uniform distribution of the reinforcement particles is necessary for the improvement in the properties of the particulate MMCs like hardness, toughness, tensile strength, etc. Stirrer al low-speed subjects the metal to lower shear forces leading to improper suspension of particles [2]. In addition, the suspended particles form clusters. The sheer force applied to the material is higher at high speeds which enables penetration of particles in the phase.Researchers exhibited the inclusion of gas particles at a higher stirring speed which in turn increases porosity.

\section{B. Time of Stirring}

It plays a very important role in the uniform distribution of dispersed phases into the matrix. Less time duration of stirring causes the clustering of the particles of reinforcement [5]. It isalso seen that some portions of the matrix were found without inclusions of the reinforcement particles. [3] On increasing the time of stirring, the distribution of the dispersed phase also increases which in turn improves the mechanical properties of the composite material.

\section{Stirring Temperature}

It is also one of the most prominent parameters which affect the stir casting processincreasing the temperature of the matrix metal the viscosity decreases and the distribution of the particles is affected. The chemical reaction between reinforcement particles and the metal matrix is accelerated by increasing the temperature of the melt.

\subsection{Nomenclature of Spur Gear}

Spur gears are the simplest form of gear (Figure 2). They have their teeth radially projected. The edge of every tooth is aligned parallel to the axis of rotation. These gears are used when motion has to be transmitted in parallel.These gears are good at moderate speeds.
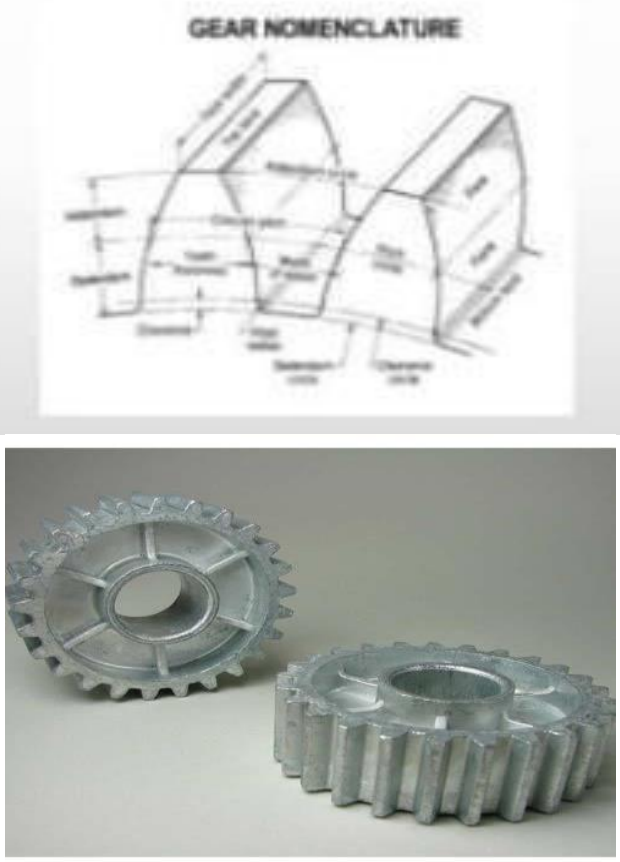

Figure 2. Nomenclature of a Gear 


\subsection{Gear Materials}

It is important to know whether sufficient strength and endurance of the teeth at their surface layers when choosing materials.

The most common material used for making gears are

Ferrous metals such as carbon steels, alloy steels such as nickel,chromium, vanadium,aluminum alloys, and cast iron of different grades

Non-ferrous metals such as brass, bronze,titanium, etc Non-metals such as plastic oriented materials like phenolic resins,nylon,bakelite,mica, etc

\subsection{Gear Failures}

Types of Gear Failures

1.Tooth Breakage

2.Pitting of Tooth Surface

3.Abrasive Wear

4.Seizing of Teeth Strength

\subsubsection{Tooth Breakage}

It is the most dangerous gear failure result of high loads of either impact or static action.repeated overloads causing low endurance fatigue. to overcome this gear material of sufficient strength will be selected (Figure 3).

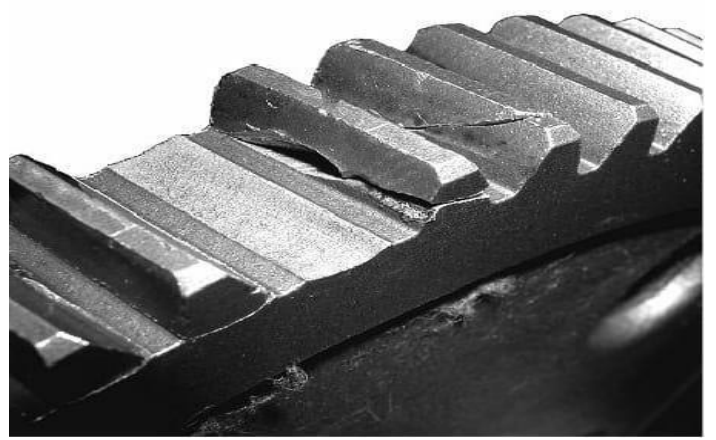

Figure 3 Tooth Breakage

\subsubsection{Pitting}

Pitting of tooth surface may happen to gears that are enclosed, lubricated, and protected against dirt. This kind of failure occurs due to over pressing of the tooth of one gear to the tooth of the mating gear. During the continuous operation, a crack may be formed which may increase in size and change into the form of pits. To prevent pitting, the teeth are checked for surface endurance.

\subsubsection{Abrasive Wear}

This wear is the reason behind the failure of gears at open and closed. This leads to a change in load and unwanted sound while transmission of power. Finally, the teeth weaken and break.Preventive measures may be taken to prevent this type of failure.

\subsubsection{Seizing}

Under utmost pressure, oil film on the teeth may vanish and cause seizing. During relative motion, the oil film is in the mesh causing the particles of softer material to leave the surface of the tooth, causing scratches on its surfaces. To prevent this, lubricant temperatures have to be maintained at a standard level.

\subsection{Gear Tooth Calculation}

\begin{tabular}{|l|c|c|c|c|}
\multicolumn{4}{|c}{ Table 1 Calculation } \\
\hline & \multicolumn{2}{|c|}{ Stir Cast Gear } & \multirow{2}{*}{$\begin{array}{c}\text { Machined } \\
\text { Gear }\end{array}$} \\
\cline { 2 - 5 } & $\mathrm{T} 7$ & $\mathrm{~T} 2$ & $\mathrm{~T} 8$ & \\
\hline H & 9.16 & 10 & 9.10 & 10.0 \\
\hline W1 & 4.10 & 4.10 & 5.14 & 6.0 \\
\hline W2 & 7 & 7 & 6.12 & 8.0 \\
\hline W3 & 8.06 & 8.06 & 7.12 & 9.0 \\
\hline
\end{tabular}

Gear tooth calculations are presented in Table1. It is very clear that due to improper selection of process parameters, defects crept in the stir cast gear and variations in parameters were also evident

\subsection{Friction Stir Welding}

This is a type of joining process in which stirring of the material happens with a tool sliding on the joint surface. This is a miniature stir casting process. Repairing of the defective material is possible with this process [8-11].

\section{Conclusion}

Gear parameters were compared with stir cast gear and machined gear. Due to discontinuity in stirring, the gear parameters of machined gear are found to be superior that stir cast gear. Development of shear force increases on rise in speed of the stirrer,which in turn results in the more uniform distribution of particles in the molten matrix. Hence by choosing proper stir casting parameters, the quality of the gear manufactured by stir casting may be matched with machined gears 


\section{References}

1. Hashim, J., Looney, L., Hashmi, M.S.J. Metal matrix composites; Production by stir casting method, Journal of Materials Processing Technology, 1999, 92-93, p.1-7.

2. Balasubramanian M, Jayabalakrishnan D, Prabhu P, Tamilselvam M, An overview of the effect of process parameters, tool geometry and joint geometry in friction stir welding and friction stir processing, International journal of applied engineering research, 2015, 10(71), pp.448-455

3. R.K. Jain, Production Technology, 16 Edition, Khanna Publishers, New Delhi (2006).

4. Jayabalakrishnan S, Balasubramanian M, Eccentricweave Friction Stir Welding between $\mathrm{Cu}$ and AA 6061T6 with reinforced Graphene nanoparticles, Materials and Manufacturing Processes 33(3), 2018, pp.333-342

5. Jayabalakrishnan D,Balasubramanian M, A Study on Friction Stir Welding on various Materials-A Review, International Journal of Engineering Technology Science and Research, 2017, 4(5), pp.247-253

6. Jayabalakrishnan D, Balasubramanian M,Friction stir weave welding (FSWW) of AA6061 aluminium alloy with a novel tool path pattern, Australian Journal of Mechanical Engineering, 17(2), 2019, pp.133-144

7. Jayabalakrishnan D, Balasubramanian M, Friction Stir Welding of Dissimilar Butt Joints with Novel Joint Geometry, Acta Physica Polonica A, 2018, 133, pp. 94100

8. Jayabalakrishnan D, Balasubramanian M, Analysis of Friction Stir Welding Between Dissimilar Materials Using Bobin Tool, International Journal of Scientific \& Technology Research, 8(12), 2019, pp.2585-2588.

9. Jayabalakrishnan D, Effect of Square Wave Tool Path Pattern on Mechanical and Microstructure Properties of Friction Stir Welded AA6061-Cu Dissimilar Alloys, Journal of the Chinese Society of Mechanical Engineers, Vol.40, No.6, pp 711 717, 2019

10. Balasubramanian M, Friction stir welding with weaving arrangement, Materials Today Proceedings, 2021, Volume 46, Part 9, 2021, Pages 3596-3600

11. Senthilkumar J,Effect of hot extrusion on mechanical and microstructural characteristics of stir cast AA6061/SiC/graphite hybrid composites, Materials Today Proceedings, 44(5), pp.3638-3641, 2021 